She remained in the hospital sixty-three days, during which she gained seven and one-half pounds; 50 c. c. antiphthisin were given her, in doses from 0.5 to 1.5 c. c.

Her appetite and general health improved. The fever, which was very variable, lessened. 'The left lung became entirely clear. The upper right improved, but the flatness in the lower right remained.

During the month following her return to her home she had more fever and lost some in weight.

CAse 24. W. Z. R., a farmer, thirty-one years old, was treated as an out-patient of the hospital from November 22, 1895, to February 6, 1896. A brother living with him had died of consumption in 1894 . In March, 1895, he had In August lie had malaria, after which his cough was worse. He had weighed 160 pounds, present weight 145 , appetite poor, coughing constantly. Bacilli tub. in sputa. His upper left lobe was dull and full of medium and fine moist râles. Antiphthisin was given him in doses of 0.5 c. c. for five days, and then by daily increase of .1 c. c. up to 1 c. c., which was given for twenty-five days in succession. His improvement was very marked, in spite of an acute abscess in the left middle ear, which caused high fever and interrupted the treatment for several days. During the following month the antiphthisin was given in larger doses, 3 c. c. having been given two days in succession, with steady lessening of the fever. In all $90 \mathrm{c}$. c. were given him. He gained eight and one-half pounds. His chest intlation increased from three and one-half to four and one-quarter inches. The râles diminished. Although doing well, he was advised to take an opportunity to remove to North Carolina, where his improvement is reported to have continued.

CASE 25. Miss B. G., seventeen years old, entered the hospital August 26, 1895. Her mother died of phthisis a year before. When four years old, she had a long siege of suppurating glands in the neck. Never a strong girl. Menstruation irregular, none since February. Has coughed for several months. Has lost 12 pounds since January, although appetite has always been good. Complexion poor, of dusky bluish tinge. Left upper lung dull to percussion, full of fine moist râles. Many bacilli tub. in sputa. Daily fever, which was increased by injections of $.001 \mathrm{c} . \mathrm{c}$. of tuberculin.

On September 9th antiphthisin was begun in doses of 0.1 c.c. For a few days the fever was apparently increased, and so again ten days afterwards, when the dose was gradually being increased to $0.5 \mathrm{c}$ c. But when, after a few days of intermission or of smaller doses, 0.5 c. c. was again given, there was not nearly so much reaction; and a month afterwards, when the dose was increased to 1 c. c. there was hardly any febrile reaction. The same treatment was continued till January 4 th. When she was transferred to the out-patient department November 13th, her cough had practically ceased. No bacilli tub. could be found in her expectoration. She weighed more than ever before, having gained $17 \frac{1}{2}$ pounds. Her fever disappeared entirely.

During the early winter she was very well, walking several miles a day or skating for several hours without fatigue. By midwinter she began to complain of pain in her "stomach." She caught cold and began to cough.

Her home was ten miles away and her infrequent visits to the hospital and lack of careful records prevented such oversight as was desirable. Occasionally she was given 1 c. c. doses of antiphthisin which she persisted produced fever. Her weight fell off four pounds. Examinations of her chest revealed no cause for her increasing debility, which was therefore ascribed to dyspepsia. On May 1, 1896 , she was re-admitted to the hospital and then the cause of the "stomach-ache" was soon apparent. The abdomen was tender and somewhat rigid. In the right iliac fossa was a tumor the size of an orange, exquisitely tender at
McBurney's point. This had probably developed only within the past few days. Surgical interference naturally followed. A few ounces of foul pus escaped from an abscess savity, the walls of which were made up of thickened omentum and mesentery. The appendix was not found, but bluish semi-translucent glands the size of a pigeon's egg were found in abundance. Some of them were dug out. Her father on seeing some of them said he had shortly before killed a cow, fat and healthy apparently, but full of the same kind of glands.

She rallied well from the operation, but has since been kept flat, the wound healing only slowly and the fever being constant. There has been no coughing since the operation but slie seems to be steadily losing ground.

CAsE 26. T. A. E., a student, seventeen years old, came to the bospitai May 10, 1895. For two months previously he had been taking antiphthisin under the care of Dr. J. T. G. Nichols, with whom I had the pleasure of serving in consultation.

The family history is negative. During the summer of 1895 he worked hard, and was in consequence somewhat run down. In December he began to cough. In January he was found to have a slight daily fever, there were râles in the left apex, and bacilli tub. in the sputa.

The disease was evidently making progress when the antiphthisin treatment was begun, March 5th, in doses of 0.5 c. c. By successive increments of 0.5 c. c. the dose was increased to 2 c. c. by April 9tl. As the daily fever grew worse the dose of antiphthisin was reduced to 1 c. c. for the first two weeks of May, and during April and May it was often given only every other day or with occasional intervals of two days. No connection favorable or unfavorable could be discovered between the administration of the antiphthisin and the daily fever. On May 10th he was moved to the hospital. His left lung has progressively degenerated. In April there seemed to be trouble at the right apex, but this has since disappeared. He does not seem as sick as his high daily fever would seem to warrant. 'The most that can be said is that while no apparent effect has followed the use of antiphthisin yet he does not seen to go down hill as rapidly as our former experience would lead us to expect. 4

\section{NUCLEINS AND NUCLEOPROTEIDS IN THEIR RELATION TO INTERNAL SECRETION.1}

BY Russell h. ChitTenden, PB.D. OF NEW Haven, conN.

Professor of Physiological Chemistry in Yale University.

The internal secretion of glands is rapidly becoming a subject of primary importance to the physiologist, and its development bids fair eventually to furnish the physician with a fund of knowledge directly applicable to the explanation of many obscure disorders, and replete with suggestions as to methods of treatment. Until quite recently the more prominent secreting glands and structures of the body have been associated solely with their obvious function of manufacturing a specific secretion or excretion to be discharged externally through special conducting tubes. The existence of so-called ductless glands, however, such as the suprarenals, thyroid, thymus, etc., with cellular structure bearing all the marks of active tissue, has long pointed to the probable manufacture in such glands of specific secretions designed solely for internal use, namely, the manufacture of substances which may be at once reabsorbed into the blood, and perhaps utilized in a variety of ways for controlling and regulating either special or general metabolism.

There is, however, no reason for limiting such a form of secretory activity to the ductless glands, for, as is quite obvious, every part of the body is the seat of some form of metabolism by which certain products result, and these in some shape may be returned

1 Read before the Massachusetts Medical Society and recommended for publication by the Society, June 10, 1896.

4his paper with illustrative charts will appear in the Transactions of the Massachusetts Medical Society. 
to the blood, and thus distributed through the body, nal secretions manufactured by the liver. kidneys, their physiological action being thereby rendered thyroid, pituitary body, suprarenals, etc., but I would available. Hence, the blood uay be in continual re- emphasize the fact that information already accumuceipt of a variety of useful substances, products of lated shows plainly that all of these glands are active the internal secretion of various glands and tissues. in the formation of internal secretions, all of which Indeed, it is quite probable that some, and possibly are endowed with marked physiological properties. all, secreting glands, even those endowed with the No doubt, too, this metubolic activity characteristic of power of manufacturing such important external these several glands results, in some cases, in the for. secretions as the pancreatic juice and the bile, are of mation of several physiologically active aubstances, greater value to the body because of the products some of greater importance than others. From this constituting their interual secretions than from their it is very evident that the general metabolism of the ability to manufacture more obvious external secretions. The truth of this assertion has been clearly established in the case of the liver and of the pan. creas, and probably also even with the kidneys. 'The complete removal of the liver and of the pancreas is, as is well known, followed very shortly by death, and this not as the result of the absence of the bile and the pancreatic juice, but rather from the deprivation of those internal secretions, emanating from these glands, which influence the general metabolism of the body.

As Hidon and others have shown, it is quite possible to destroy the ordinary secreting cells of the pancreas, thus doing away entirely with the production of pancreatic juice, without any of those symptoms so characteristic of the entire removal of the gland. If, however, the gland is entirely removed, symptoms of glycosuria at once appear, and the animal speedily dies. Further, if in extirpating the pancreas a small portion of the gland is left, this residue of glandular tissue may be sufficient to prevent the appearance of serious symptoms. Or, if a small piece of pancreas from some other animal is grafted on, either into the peritoneal cavity or even under the skin, the entire pancreas may then be removed without the appearance of glycosuria. In other words, we have in these facts pretty certain evidence that the pancreatic gland manufactures something, in small amount perhaps, which is eventually poured into the blood, aud which prevents the excessive formation of sugar in the body, or enables the body to burn the sugar that may be formed.

This, then, may be taken as an illustration of the importance of internal secretion, since in this gland, which plainly has an important function in the manufacture of the pancreatic juice, there is formed something absolutely essential for the physiological equilibrium of the body; sometbing which is thrown into the blood current, and without which the body cannot thrive. 'This is unquestionably not true of all glands, at least to the same extent. Thus, in regard to the salivary glands, or more particularly the parotids and submaxillary glands of the dog, Schäfer ${ }^{2}$ has very recently shown that these glands, unlike the pancreas, do not furnish any specific secretion necessary to the life of the animal or having any important action upon any of the metabolic processes. At least, the complete removal of these glands does not noticeably impair the nutrition of the animal, from which we must infer that if any internal secretion is supplied by these glands "it must be one common in character and function with that of some other organ, or at least one which can with ease be vicariously supplied by another organ."

It is not my purpose here, however, to enter into detail regarding our knowledge concerning the inter-

\& Journal of Physlol., Vol. xix, No. 4. Proceed. Pbysiol. Soc. body must be more complex even than hitherto supposed, and that many of the functions of the body are dependent upon other functions more or less obscure.

The manufacture of the specific substances which give character to the various internal secretions is obviously a function either of special cells contained in the gland, or it may be in some cuses an inherent quality of all the cellular elements of a given gland. In the pancreas, the formation of the active agent is apparently limited to an interstitial epithelium-like tissue occurring in isolated patches throughout the gland, and especially characterized by its vascularity. This epithelooid tissue is certainly distinct from the secreting alveoli, and is suspected at least of being the source of the internal secretion. Again, in the suprarenals, as Schäfer and Oliver have shown, the active principle, which has such a marked influence upon the heart and arteries, is contained only in the medulla of the gland and not in the cortex, the medulla forming about one-fourth of the gland by weight.

However specialized the cells concerned in the manufacture of these physiologically active substances may be, they are certainly typical cells with distinct nuclear protoplasm and cytoplasm, and if one is to unravel the nature of the chemical processes by which the active ageuts are produced and learn their true origin, as well as their exact chemical structure, it becomes necessary to study the character of the material of which the cells are composed, and out of which the physiologically active principles are constructed. It is quite proper to say that these bodies originate through the metabolic activity of the cell, but such a statement carries with it little exact knowledge and throws little light upon either the nature of the process or the character of the resultant products. Further, as already indicated, we must not limit our conception of internal secretion to a few isolated glands, but keep clearly in mind the fact that wherever there is metabolic activity absorption of products is liable to occur, and is no doubt a constant feature of all glands and tissues, alchough obviously not all organs yield katabolic products of vital importance. Yet, doubtless all of the so-called leucomaines formed throughout the bory, especially in the muscular tissue and glandular organs, innocent though they are of any marked physiological action, do have functional power and are of aid in keeping up that physiological equilibrium so essential to the well-being of the body, and for the smooth running of the vital machivery. We know well that any excessive accumulation of these normal leucomaines gives rise to noticeable disturbance of the system, and we already associate their presence under such conditions with definite symptoms. Why then should we not attribute some power to these substances when present in nor- 
mal quantities, and give full recognition to their possible value as interual secretions?

In this broader sense, then, internal secretion must be going on all through the body and this aspect of the subject truly merits our careful cousideration. At the present time, however, interest naturally centres around those more striking phenomena which pertain to those internal secretions, study of which has furnished clear proof of their vital importance. The physician well knows that failure of one or other of these interual secretions is a matter of vital import, while the recognition of such failure is vecessarily the first step in the process of treatment. Again, experience has already shown that the physician may hope to avail himself of the active principles which the internally secreting glands afford, and in certain cases to use either their extracts or the active principles themselves in place of the hitherto more commonly employed regetable medicaments.

Chemically considered, we have to-day a certain amount of knowledge concerning the nature of the active substances secreted by the thyroid gland and the suprarenals. In the case of the latter glands, the active principle is a body soluble in water and in dilute alcohol, insoluble in absolute alcohol, ether, chloroform, benzine, amyl alcohol, etc. In aqueous solution, it dialyzes readily through parchment, the diffusate being entirely free from proteid. Hence, the active principle cannot be a proteid body. It is, moreover, fairly stable, not being destroyed by moderate boiling, nor hy the action of acids, and it is also fairly resistant to the action of the gastric juice. It is, however, readily destroyed, that is, its physiological power is lost, through the action of alkalies, by oxidizing agents, and by continued boiling. It is apparently a powerful reducing body, and by oxidation, as with hydrogeu peroxide, or with alkalies in the presence of oxygen, a rose-red color is produced accompanied by rapid loss of physiological action. As to more definite knowledge concerning the chemical nature of the substance, we know nothing. It is plainly a very active substance, for as Schäfer and Oliver have shown, $5 \frac{1}{2}$ milligrammes of the dessicated suprarenal gland are sufficient to obtain a maximal effect upon the heart and arteries in a dog weighing 10 kilogrammes. But as the active principle is contained only in the medulla of the gland, and this does not form more than one-fourth of the gland by weight, and as full nine-tenths of the medulla are composed of proteid and other non-diffusible matter, it is calculated that $\frac{1}{80}$ of a grain of the pure active principle is sufficient to produce distinct physiological results upon the heart aud arteries of an adult man. The conclusion is therefore obvious that the actual amount of this substance elaborated by the suprarenal gland is exceedingly small, a fact which plainly stands in the way of a more thorough study of its properties. Enough is known, however, to show that this substance, which is of primary importance to the body, must result from very decided metabolic changes. Assuming its origin to be some one or more of the proteid molecules of the cell, it is plain from the nou-proteid nature of the substance that its manufacture must be attended with profound secretory changes.

In the case of the thyroid gland we have evidence, tbauks to the painstaking work of Baumann and his colleagues, that the physiologically active substance of this gland is an organic iodine compound - thyroiodin.
This body manifests no proteid reactions, though on decomposition by heat it evolves an odor of pyridin bases. It contains a large proportion of nitrogen, aud about 0.5 per cent. of phosphorus in organic combination, a fact which suggests the possibility of its being a direct cleavage product of nucleic acid. Thyroiodin can be prepared from the thyroid glands of man and animals, by boiling the glands with sulphuric acid, or by treating them with artificial digestive fluids, a fact which testifies to the comparative stability of the active substance. When purified, it possesses weak acid properties, is readily dissolved by alkalies and in part by cold water. The iodine is in very firm combination, and is present in the molecule to the extent of 10 per cent. Only a small proportion of the thyroiodin obtainable from the glaud exists in a free state, the bulk of the substance being combined with two pruteids an albumin and a globulin - the former predominating. From these compounds thyroiodin can be split off by the action of dilute sulphuric acid. Repeated experiments have demonstrated that the physiological activity of the thyroid gland, so noticeable in myxedema, adipositas, etc., is due solely to the thyroiodiu, and it is to be noted that excessive doses of this compound give rise to the same toxic symptoms that are frequently produced by the ingestion of large quantities of thyroid glands. This active principle of the gland undoubtedly makes it way to other organs. Baumann, indeed, has detected iodine in the thymus of the calf, and Professor Miculicz of Breslau bas observed a decrease in the size of thyroids in goitre after repeated ingestion of thymus glands. At the same time it is evident that thyroiodin is not a product of general metabolism, but its formation is apparently restricted to the thyroid gland, although the product once formed may be utilized in a variety of ways, and doubtless in different parts of the body.

All of the secretions of the body emanate from the functionally active cells of the various glands and organs, and the origin of the internal secretions is to be sought for in the metabolism of the gland cell. In the evolution and development of the different glands of the body we bave tangible evidence of morphological differentiation, both as regards external form and as regards the constituent cells, and this no doubt is accompanied by a corresponding functional or chemical differentiation, the extent of which we are wont to measure by the variations in chemical composition, either of the gland or tissue as a whole, or of the external secretion which it manufactures. To this must now be added the composition and function of the internal secretions, which give a still wider variety to the many functions of the body. How are we to explain this variety of function so characteristic of the different glands? Where are we to seek for the origin of the many diverse products which are found in the different secreting structures? To the chemist only one explanation seems probable, namely: that the different gland cells must be endowed with a distinctive form of cell protoplasm, and when this is called into activity under normal circumstances certain products invariably result from the very nature of the protoplasm, that is, from its peculiar chemical constitution. Every gland, organ and tissue of the body must therefore have its own particular kind of cell, and this personality is not to be cousidered as restricted to its morphology, but as applicable also to the chemical constitution of its cell protoplasm, upon 
which rests its function. In every animal cell we recognize at least two physiologically distiuct parts, the nucleus with its contained karyoplasm and the body of the cell with its constituent cytoplasm, and in my judgment the so-culled inherent qualities of a cell its functional power - reside in the chemical nature of the groups and radicles which enter into the karyoplasm and cytoplasm.

According to this view functional differentiation is dependent upon the character of the anabolic processes; it is this which determines in great part the nature of the cell and the character of the products resulting from its activity. Hence, cell protoplasm is not an entity of ever constant chemical composition common to the cells of all glands and tissues, and yielding different products in different localities according to nerve or other influence exerted by the peculiar environment, but on the other hand, there must be a typical form of cell protoplasm for each distinct group of cells, each form with enough individuality to admit of its certain detection on application of the proper tests. Abuormality of function may thus be due as much or more to perversion of the anabolic processes of a cell or group of cells, as to any direct modification of the katabolic processes; in other words, modification of the anabolic processes results in the formation of what might be called an abnormal protoplasm, and this necessarily leads to the formation of peculiar or abnormal products, recoguition of which constitutes the best and perhaps only proof of the abnormality.

'These views being correct, it is quite misleading to speak in the general way frequently adopted of cell protoplasm and its primary constituents. In other words, the primary constituents of one group of cells, as in the thymus, for example, must be of a different nature from those common to the protoplasm of the liver cells. Hence, there are no primary constituents common to all forms of cell protoplasm, but each variety of cytoplasm and karyoplasm, in my judgment, has its own peculiar make up. By this I do not mean that the various forms of cell protoplasm necessarily existent in the human body are superficially, at least, as varied in composition as the products which emanate from the activity of the various glands and tissues. With large and conplex molecules, such as are common to living protoplasm, considerable variety may be introduced into the structure without leading to any very great external difference, but if we could only unravel and spread out before us the many simple groups that enter into the make up of the varied forms of complex protoplasm, I fancy the differences would be even more striking than is suggested by the character of the products which result from the breaking down of the various forms of glandular protoplasm.

Superficially, however, cell protoplasm, whatever its origin, has a certain uniformity of composition, and the body or bodies which stand out most prominently as characteristic of the cytoplasm and karyoplasm of all active cells, are a peculiar group of compound proteids known as nucleoalbumius or nucleoproteids, all characterized by containing more or less phosphorus. A few years ago our knowledge of these bodies was very limited - and indeed it is none too complete to-day - but recently our knowledge has been growing very rapidly and we are learning that under the name of nucleoproteids, nucleoalbumins, nucleins and nucleic acids we have to deal with a class of very remarkable bodies which constitute the greater part of the nucleus and cytoplasm of vearly all celle, and which evidently play an all-important part in every form of cell metabolism. Proteid or albuminous bodies have long been known as the chief constituents of protoplasm, but we now understand that it is not as simple proteids that these bodies exist in the cell, but mainly as conpound bodies, that is, as combinations of nucleic acid with some form of proteid or albuminous matter.

Between the cytoplasm and karyoplasm of a cell the cytologist recognizes a distinct and usually constant difference, which shows itself at once on the application of appropriate dyes. The nucleus of the cell we say is rich in nuclein, while the cytoplasm, and perhaps the nucleoli as well, are characterized by the presence of nucleoalbumin with a less marked allinity for dyes. But nucleins and nucleoalbumins or nucleo. proteids differ from each other simply in the proportion of proteid and nucleic acid which they contuin. The bodies of this class are all acid bodies, of weak acidity to be sure, and with a varying degree of acidity, but sufficiently marked in every case to suggest the presence of some form of acid radicles. 'This fact, indeed, led to the discovery of nucleic acids, bodies readily obtainable from all forms of true nucleins by the action of dilute alkalies, the latter seeming to break up the combination existing between the acid and the albuminous matter with which it is naturally combined. A so-called nuclein is thus seen to be simply a combination of some form of proteid matter with a nucleic acid, while a true nucleoproteid or nucleoalbumin is a combination of a nuclein with more albuminous matter.

Nucleic acid, as ordinarily prepared, is a white amorphous powder of strong acid reaction, readily soluble in water containing a small anount of alkali, and with a strong affinity for proteid matter of all kinds. In composition, uucleic acid is characterized by its large percentage of phosphorus, as much as 9 or 10 per cent. of this element being found in some forms of this acid. According to Kossel, the proportion of nitrogen and phosphorus in all nucleic acids is as three to one. But while all forms of nucleic acid may contain a certain definite proportion of nitrogen and phosphorus, they differ from each other very decidedly in their inner structure, as indicated by the character of their cleavage products. Indeed, it was only by studying the decomposition products of nucleic acid from various sources that a suggestion was obtained of the existence of different forms of this acid. Thus, if the nucleic acid separated from the cells of the thymus gland be boiled with dilute sulphuric acid it yields a large amount of a peculiar nitrogenous base called adenin, with some guanin and the new base, cytosin. On the other hand, the nucleic acid obtainable from the sperm of steers yields by similar treatment not adeuin, but mainly xauthin, hence this acid may be appropriately termed xauthylic acid. Again, the nucleic acid obtainable from yeast cells yields on decomposition four distinct nitrogeuous bases, namely, xauthin, guanin, adenin and hypoxanthin, from which we infer that this particular acid is in reality composed of several, possibly four, distinct varieties of nucleic acid.

Another fact which implies the existence of even a greater variety of nucleic acids is found in the presence of carbohydrate groups in some acids. Thus, the nucleic acids obtainable from the cells of the pancreatic and mammary glands, as well as those prepared from yeast cells, yield by cleavage a reduciug carbohydrate, 
while from the acid of the thymus gland, levulinic acid has been obtained. In some other forms of nucleic acid, on the other haud, no carbohydrate groups can be detected. Again, there are some forms of nucleic acid - so-called paranucleic acids - from which no nuclein bases whatever can be obtained by decomposition. Hence, it is very evident that under the head of nucleic acids we have to deal with a large class of closely related bodies, superficially showing a close resemblance in general reactions and properties, but with a diversity in inner structure clearly suggestive of corresponding differences of function.

Some one or more of these acids are to be found in every active cell of the body, generally not free, but ordinarily combined with more or less proteid matter of some kind to form the various vucleoproteids and nucleins which, in great part, compose the karyoplasm and cytoplasm of all living cells. The properties and general characters of the nucleoproteids and nucleins, and hence likewise of the karyoplasm and cytoplasm of the cell, depend maiuly upon the amount and character of the uucleic acid united to the proteid. Generally, the vuclear protoplasm is rich in nucleic acid as indicated by its high content of phosphorus and by the character of the stain yielded by certain dyes. The cytoplasm, on the other hand, usually contains a smaller proportion of nucleic acid with a larger admixture of proteids ; that is, the cytoplasm is mainly composed of nucleoproteids with a comparatively low content of phosphorus. Variations in the amount and character of the nucleic acids, as well as of the proteid, existent in the nucleins and nucleoproteids of cell karyoplasm and cytoplasm obviously affect the ordinary reactions of the protoplasm; but of still greater importance, physiologically, is the influence exerted by this variability in determining the functional peculiarities of cell protoplasm; a variability which may well be assumed as all-sufficient to account for the peculiar lines of metabolism characteristic of the individual glands and tissues of the body.

If we take the content of phosphorus as a measure of the proportion of nucleic acid contained in the various forms of nucleoproteids thus far studied, we find exceedingly great variations in the amount of this acid present in the molecule; a fact which may be taken as evidence of the large number of molecular combinations present in the protoplasm of different cells. Thus, from the kidneys we obtain a nucleoproteid with only 0.37 per cent. of phosphorus, while as representing the other extreme we have in the pancreas a nucleoproteid containing 4.71 per cent. of phosphorus, and in the lymphoid cells of the thymus a corresponding body with 3.5 per cent. of phosphorus. While these various combinations, modifying as they do the composition of the cell protoplasm, are of the greatest moment in determining the metabolic activity of the cell, of far greater importance is the variable character of the nucleic acid present in the plasma, since this introduces an element which may well determine the line of metabolism. Variation in the quality and quantity of the chemical material entering into the structure of the karyoplasm and cytoplasm of the cells of the body is thus clearly indicated, and the character of the most variable elements - the nucleic acids may well attract our attention as offering a tangible explanation of one cause, at least, of the striking individuality of the various gland cells. In the structure of the individual nucleic acids, with their marked tendency to yield specific nitrogenous bases, bodies which are common katabolic products of many glauds and tissues, we see a plausible opportunity for explaining the origin of many substances characteristic of both external and internal secretions. I must admit there is wuch that is theoretical in this suggestion, but I know of no line of study which offers equal inducements in the way of explaining the origin of the peculiar bodies which give character to the internal secretions. The very uature of the many bases which come from the cleavage of the nucleic acids outside of the body; the ready convertibility of these bases into other allied bodies by oxidation and reduction; their own physiological action, which though mild is marked; the possibility, nay the probability, that many other katobolic products may be obtained from these nucleic acids; and further that still other nucleic acids, at present undiscovered, may exist in the cell protoplasm; all offer good reasons for believing that the nucleins and nucleoproteids, which are the most prominent constituents of the protoplasm of all cells, are the most probable antecedents of the internal secretions.

In conclusion, allow me to say with reference to nucleins and nucleoproteids that due consideration should be given to the probable difference in physiological action of the several nucleic acids. We all, I am sure, believe in the close relationship existing between chemical constitution and physiological action, and since. it is very evident that the specific nucleic acid of the thymus is quite different in chemical constitution from xanthylic acid, for example, it follows that corresponding differences iu physiological action may likewise exist. Consequently, if so-called nuclein therapy is to have a legitimate trial it is to be hoped that ultimately distinct forms of nucleic acid, nucleins, etc., may be available for the use of the pharmacologist and the clinician.

CASES OF ABDOMINAL SURGERY OCCURRING IN 'THE FIRS'T SURGICAL SERVICE UF 'THE BOSTON CITY HOSPITAL DURING THE FOUR MON'THS' SUMMER SERVICE OF 1895.

BY FRANCIS 8. WATSON, M.D., Visiting Surgeon.

'ThIs series comprises 50 cases, and includes all those in which abdominal section was performed during the time mentioned above, with one exception, that of a case of excision of the gall-bladder and a portion of the liver for malignaut disease, which was done in 1894.

In 43 of the total number, the operations were doue by the writer, in the other seven, by Drs. Post, Mouks, Munro and Lovett.

The report is presented in two parts, of which this, containing 22 cases, is the first.

Seven cases have already been published by this JoURNaL separately, because of their importance, in fuller detail than would be possible for the whole; they are the last mentioned in the list, and with them will be found references to the numbers of this JOURNAL in which they appeared.

Septic infection of the wound occurred in five out of the whole number of cases, in the form of stitchabscess; in three cases of hernia and of general wound infection in two.

The cases are as follows : 